\title{
Hunting dogs as environmental adaptations in Jōmon Japan
}

\author{
Angela R. Perri ${ }^{1}$
}

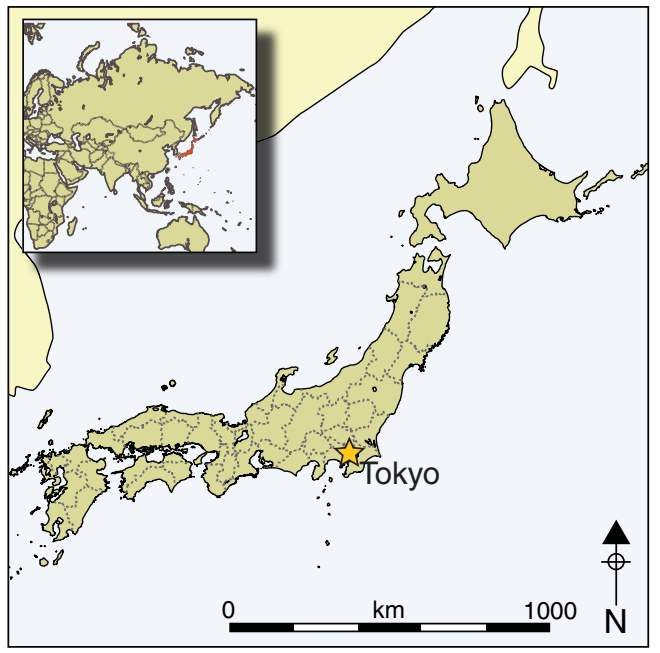

Was the use of hunting dogs an adaptation to the post-glacial deciduous forest environment in the northern temperate zone? Dog burials in Jomon Japan appear closely associated with a specific environment and with a related subsistence economy involving the hunting of forest ungulates such as sika deer and wild boar. Dogs were valued as important hunting technology, able to track and retrieve wounded animals in difficult, forested environments, or holding them until the hunter made the final kill. Greater numbers of dog burials during the later Jomon phases may reflect a growing dependence on hunting dogs to extract ungulate prey from forests in an increasingly resource-strained seasonal environment.

Keywords: Japan, Jōmon, dog burial, hunting

\section{Introduction}

The Jōmon culture of Japan (c. 12500-2350 BP; Table 1) is considered one of the best contexts for analysing complex prehistoric hunter-gatherer groups (Rowley-Conwy 2001). Although often discussed as a single culture that dominated the archipelago for over 10000 years, the Jōmon actually comprised various subgroups with differing traits across regions (Bleed \& Matsui 2010). These traits were specifically defined by the geography and climate of the various latitudinal zones from subarctic to subtropical, a result of the extreme north-south orientation of the islands. This variation in climatic conditions meant that subsistence systems practised by Jōmon hunter-gatherers in each area were highly varied, with different prey species, tool technology, hunting methods and environmental adaptations (Underhill \& Habu 2006). Even within a small area in Japan, a mosaic of

1 Department of Human Evolution, Max Planck Institute for Evolutionary Anthropology, Deutscher Platz 6, Leipzig 04103, Germany (Email: angela.perri@eva.mpg.de) 
Table 1. Dates of the Jōmon phases.

\begin{tabular}{lc}
\hline Incipient & c. $16140-10000 \mathrm{BP}$ \\
Initial & c. $10000-7000 \mathrm{BP}$ \\
Early & c. $7000-5450 \mathrm{BP}$ \\
Middle & c. $5450-4420 \mathrm{BP}$ \\
Late & c. $4420-3220 \mathrm{BP}$ \\
Final & c. $3220-2350 \mathrm{BP}$ \\
\hline
\end{tabular}

different environments is possible. Due to these variables, different degrees of complexity can be expected among the various Jōmon subcultures.

This paper focuses on the Jomon subculture that inhabited the eastern side of the main island, Honshu, hereafter referred to as the Pacific Honshu Jōmon (Figure 1). At the beginning of the Holocene, this region of Japan experienced a distinctive transition to environmental conditions that allowed Jōmon foragers to flourish in a forest-estuary ecotone consisting of abundant, nut-bearing deciduous trees, shellfish, coastal fish and forest ungulates such as sika deer (Cervus nippon) and wild boar (Sus scrofa leucomystax), which made up the majority of their diet. Also unique to this part of Jōmon Japan is the occurrence of the individual burials of domesticated dogs (Canis familiaris), only a few of which have previously been discussed outside of the Japanese literature. Researchers have long presumed that hunting dogs were kept by Jōmon foragers (e.g. Kraus 1953; Nishinakagawa et al. 1994), and in Japan "boar-hunting with dogs is seen as a quintessential Jōmon activity" (Knight 2003: 153). Yet this idea has not moved beyond the theoretical, even though archaeological dog remains have been systematically surveyed across Japan (see Kaneko 1978; Shigehara 1985; Niwa 1987; Kojima \& Kikuchi 1999). Here, I discuss a possible relationship between the isolated clustering of Jōmon dog burials in just one region and the specialised adaptations to changing environments and prey in this locality. I document a strong association between the first appearance of Jōmon dog burials in eastern Honshu and a shift to primarily hunting terrestrial ungulates in the new Holocene deciduous forests of the region, signifying the probable use of dogs as a dense-forest hunting adaptation after the Pleistocene-Holocene transition.

\section{Palaeoenvironments, subsistence and regional variation}

The Japanese islands have a largely mountainous terrain with areas of low-lying coastal plains and a longitudinal orientation that creates distinct environmental regions from north-south (Figure 2). As with other areas of the northern temperate zone, the Pleistocene-Holocene transition brought about significant and rapid climate change in Japan (see Yasuda 1978). Prior to the transition, the islands were mainly covered by conifer forests. The onset of warming in the early Holocene triggered a dramatic vegetation change, with temperate deciduous forests, which had been in retreat in the southern islands, spreading north onto the main island of Honshu (Aikens \& Akazawa 1996). This environmental shift, in combination with the topographic and latitudinal range of the islands, led to the creation of new exploitation niches for Jōmon foragers, including important variations in plant 


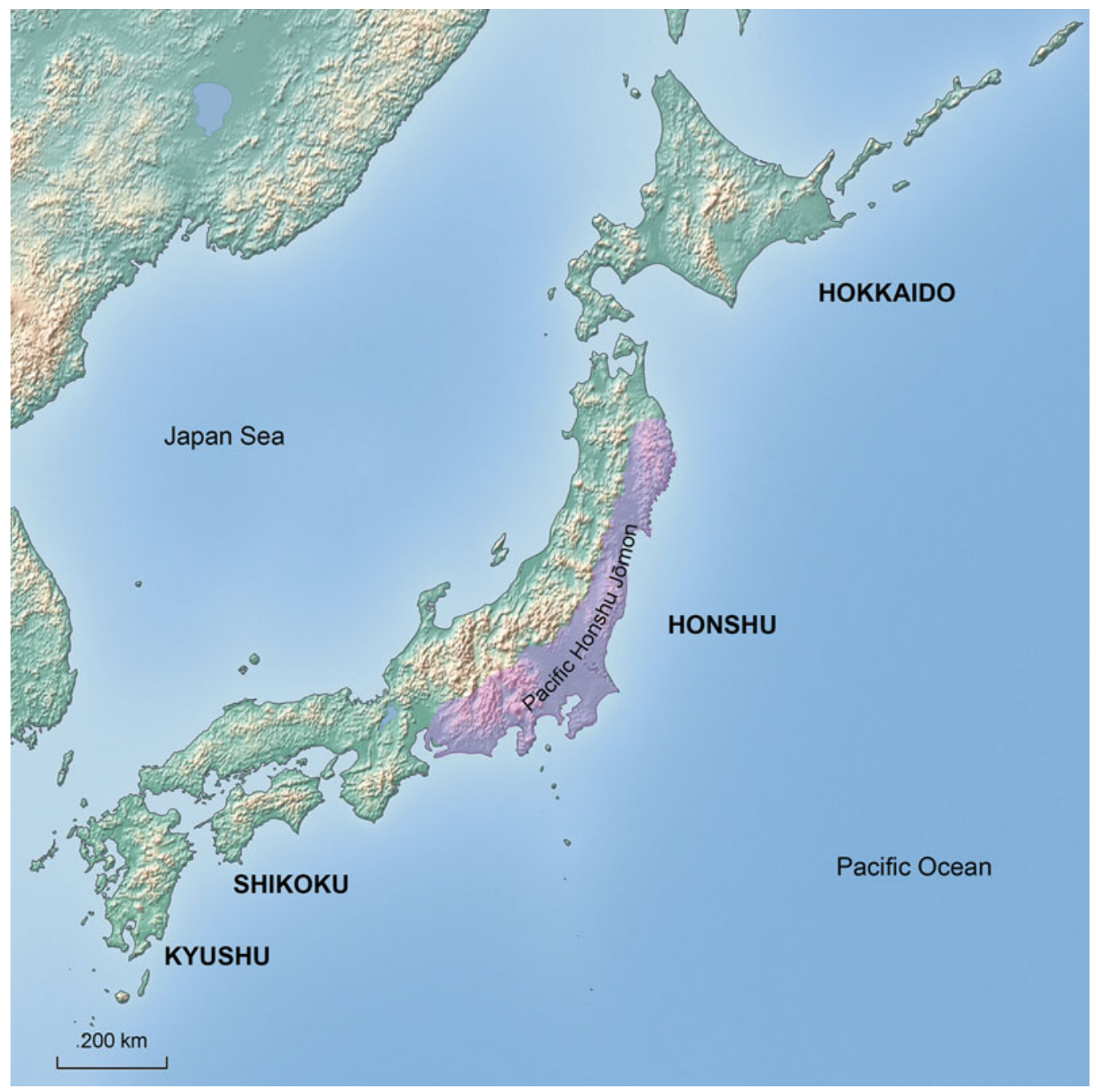

Figure 1. Map of Japan with the location of the Pacific Honshu Jommon region.

availability, coastal resources and terrestrial prey species. In contrast to the oft-cited seasonal, broad-spectrum Jōmon diet (see the 'Jōmon Calendar'; Kobayashi et al. 1992), the different Jōmon subcultures may have aligned much more with Binford's (1980) theory of collectors: specialists who rely on a few key resources (Aikens et al. 1986; Habu 2004). Leaving aside the subarctic and subtropical environments on the extreme northern and southern islands, regional variation-reflected in the analysis of subsistence remains, dietary isotopes and tool kits_resulted in three generalised subsistence niches on the main islands (e.g. Akazawa 1986; Minagawa 2001; Hoover \& Williams in press): Hokkaido and the northern border of Honshu with primarily marine mammals and fish; south-western Honshu and the southern islands with primarily plant and marine foods; and north-central Honshu with mixed economy with terrestrial animals, plants and marine foods.

(C) Antiquity Publications Ltd, 2016 


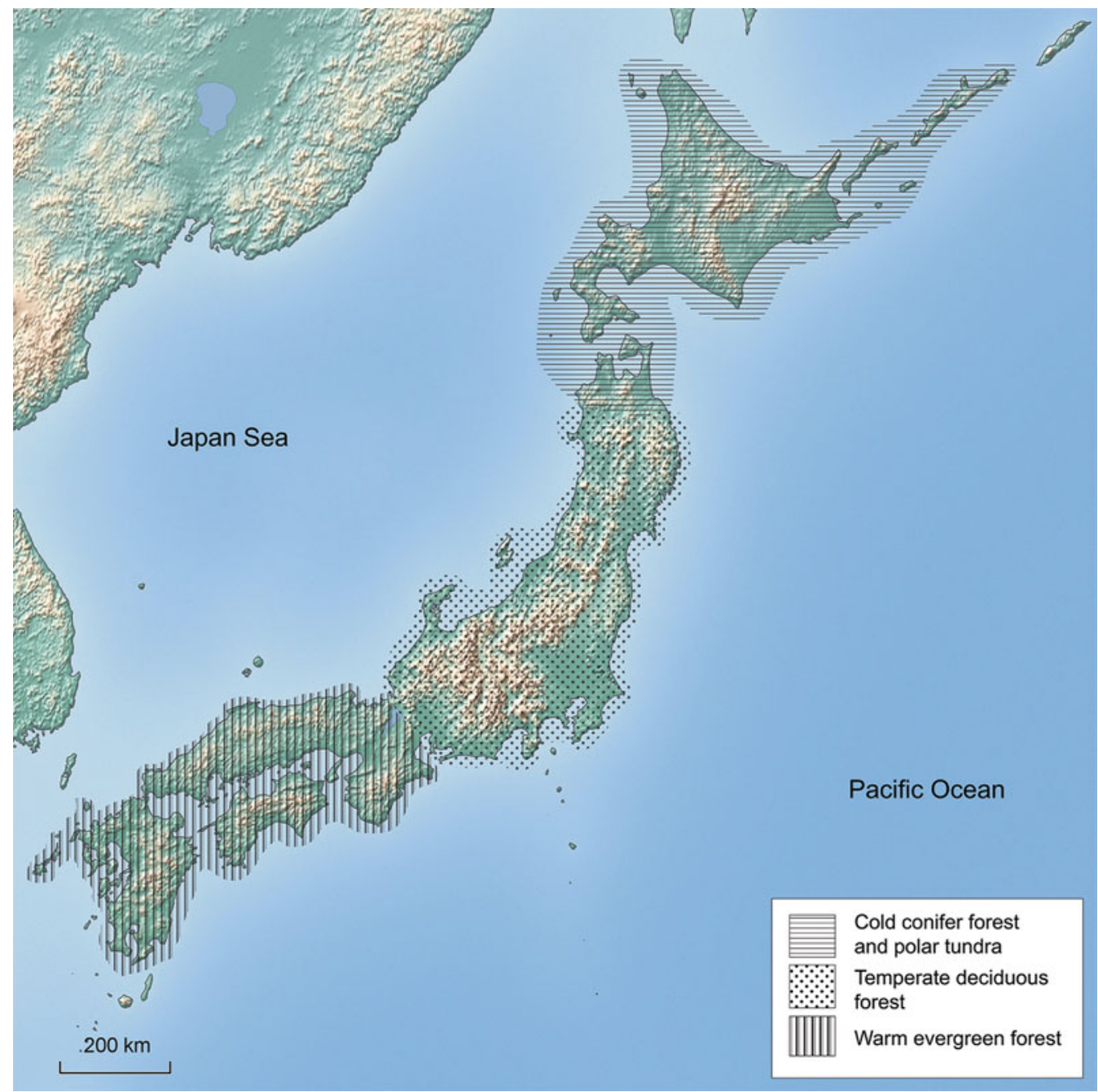

Figure 2. General environments across Japan during the Jōmon period (adapted from Tsuji 2001).

\section{The Jömon of Pacific Coast Honshu}

The spread of deciduous forests into north-central Honshu increased the variety of edible plant foods and strengthened the habitat for forest ungulates. This led to flourishing Jōmon populations, particularly along the Pacific coast (Aikens \& Akazawa 1996; Habu 2004). Here, post-glacial rising sea levels also increased coastal biotic productivity, resulting in a proliferation of large shell midden sites along the low-lying coastal plains (Habu et al. 2011). The convergence of abundant upland deciduous forests and coastal resources created an ecotone unparalleled in other regions of Jōmon Japan. Akazawa (1986) and Uchiyama (2006) speculate that the majority of large Jōmon settlements were located in this region due to a productive transitional zone, allowing for the use of both coastal and forest resources within a minimal distance. 
Post-glacial shifts of flora and fauna in north-central Honshu prompted a reorganisation of subsistence strategies, requiring adaptations away from hunting the large terrestrial megafauna of the Pleistocene-e.g. Naumann's elephant (Palaeoloxodon naumanni) and Yabe's giant deer (Sinomegaceros yabei) — and towards a strategy of taking smaller, quicker ungulates in a densely forested environment (Inada 1986; Tsuji 1997). Changes in prey are reflected in the technological advances seen from the region, including a shift to smaller, triangular points used for the bow and arrow (Aikens \& Higuchi 1982; Inada 1986), which were designed to induce heavy bleeding in ungulates (Friis-Hansen 1990; Churchill 1993). This change in blade technology began in the southern islands, moving north with the changing biota, suggesting strong connections between Jōmon environmental and cultural changes (Aikens \& Akazawa 1996).

In the temperate deciduous forests of north-central Honshu, there may have been variation between Jōmon on the Japan Sea and Pacific coasts, with an increased reliance on plant resources along the Japan Sea, although more dietary isotopic work is needed for this region. The Japan Sea coast, west of the central mountain range, is well known for its heavy, longlasting snowfall, which sika deer and boar migrate to avoid (Tsujino et al. 2010). Minaki (1988) suggests that extensive chestnut cultivation occurred along this coast, with raisedfloor longhouses - associated with the winter storage of nuts in high snowfall areas-found predominantly in this region (Kitagawa \& Yasuda 2008). In contrast, a substantial primary dependence on sika deer and wild boar by Jōmon on the Pacific Honshu coast has long been established by researchers (Koike 1986; Hongo et al. 2007). In these two productive temperate forest environments, however, the importance of ungulate hunting on the Pacific coast, as compared to the Japan Sea coast, is probably closely related to the availability of prey during the key autumn and winter months.

It is important to note that in addition to regional variation, there is significant temporal and population variation during the Jōmon phases, which cannot be thoroughly discussed here. In Pacific Honshu, populations were generally higher than in the rest of Japan, probably due to the productive environment and access to a variety of resources. Populations in Honshu appear to have peaked in the Middle phase with a decline in the later phases, although the number of shell midden sites increases in these later phases (Habu et al. 2011). In contrast, populations in south-western Japan begin small, increasing through the later phases, suggesting either dispersal from highly populated Honshu, an influx of groups from mainland Asia, or both. Climatic and environmental fluctuations during the Jōmon phases_-including dramatic sea-level rise between 7400-5900 BP known as the Jōmon Transgression, and a cooling period during the Late and Final phases (Tsukada 1986)_probably contributed to these population variations.

\section{Dogs as hunting technology}

A hunting partnership between dogs and humans has long been postulated in the archaeological literature, with some researchers suggesting that such a collaborative alliance was the basis for the initial domestication of dogs (e.g. Davis 1982; Clutton-Brock 1995). A partnership of this nature has often been proposed between Jōmon hunters and their dogs, given that terrestrial game hunting was an important part of the subsistence economy of

(C) Antiquity Publications Ltd, 2016 
some regional subgroups (Nishinakagawa et al. 1994; Kobayashi 2004). The shift in hunting strategies following the Pleistocene-Holocene transition probably included hunting dogs as a combined, dense-forest technological innovation along with the bow and arrow. The innate ability of a dog to sniff out, track, chase and hold prey can significantly enhance the success of human hunters in forested environments (e.g. Dwyer 1983; Ngima Mawoung 2006). Dogs are an important, and in some cases indispensable, hunting aid for many modern forager groups, as they probably were for foragers in prehistory. Their use is often a critical factor in the minimisation of subsistence risk and the maximising of hunting returns; they can prove an invaluable extension of the hunter and their toolkit (Mitchell 2008).

The rapid spread of post-glacial temperate forests in north-central Japan increased the total ungulate biomass, which may have been a crucial variable in human behaviour, organisation and populations in the early Holocene (Mellars 1975; Rowley-Conwy 1986). These areas of high-value prey species were ideal hunting grounds for the Jōmon, yet the density of the temperate forests and swiftness of medium-sized ungulates would have required adapted hunting methods compared to the more open habitats and large herd animals of the previous glacial period. Clutton-Brock (1984) suggests that hunting dogs were heavily used in the early Holocene - in conjunction with microlith technology - to track and retrieve wounded game in difficult, forested environments. Wild boar are particularly sensitive to vegetation type, preferentially inhabiting areas with the densest cover (Melis et al. 2009; Said et al. 2012), making dogs particularly useful for boar hunting.

The use of dogs as hunting tools is widespread in the ethnographic literature, especially in the hunting of deer and wild boar in forested environments (e.g. Ngima Mawoung 2006; Pannell \& O'Connor 2010). Modern hunters emphasise the importance of hunting dogs in dense woodland, where human sensory and locomotor skills are diminished (e.g. Ellen 1999; Chitwood et al. 2011). Injured deer often run, leading hunters on long chases, and wild boar can be aggressive and quickly learn to evade capture. Hunting dogs mitigate these factors by tracking blood trails, forcing game into vulnerable positions (e.g. in water) and holding prey until the hunter can make the final kill (Rühe et al. 2006; Said et al. 2012). Specifically, the successful hunting of wild boar often requires highly skilled dogs, which are prized above all others, and without which many hunters attest boar hunting would be virtually impossible (Bulmer 1968; Dwyer 1983). The effectiveness of hunting dogs in the Pacific Coast Jōmon environment, along with the presence of many dog burials in this region, indicates that Jōmon hunters were probably using dogs as tools for the hunting of sika deer and wild boar, as hunters in Japan still do today.

\section{Jōmon dog burials}

Due to their significant contributions to the subsistence economy of some forager groups, the ethnographic record is full of examples of the revered treatment of hunting dogs. They are often given proper names, treated as members of the family and considered separate from all other dogs (e.g. Ikeya 1994). This treatment frequently extends to the burial of hunting dogs in remarkably human-esque ways, often with grave goods and markers (e.g. Grøn \& Turov 2007; Koler-Matznick et al. 2007). Dogs that are exceptional hunters or that die during a hunting expedition are often particularly venerated (e.g. Olowo Ojoade 1990). 
Table 2. Number of sites and dog burials assigned to each Jōmon phase; some burials come from multi-phase sites where the burial has not been assigned to a particular phase; + denotes phases with additional burials identified, but the exact number is unknown.

\begin{tabular}{lcc}
\hline Phase & Sites & Burials \\
\hline & & \\
Initial & 2 & 3 \\
Early & 3 & $2+$ \\
Early-Final & 1 & 3 \\
Middle & 8 & $34+$ \\
Middle-Late & 3 & $2+$ \\
Middle-Final & 1 & + \\
Late & 7 & $15+$ \\
Late-Final & 7 & $16+$ \\
Final & 6 & $35+$ \\
Jōmon (general; date not given) & 1 & + \\
TOTAL & $\mathbf{3 9}$ & $\mathbf{1 1 0 +}$ \\
\hline
\end{tabular}

Their value as important hunting companions affords the possibility of status: they are a living weapon that can seemingly be elevated to 'personhood' based on their skills as an individual. The same may have been true for valuable hunting dogs in the past, especially in an egalitarian society such as the Pacific Coast Jōmon (cf. Mizoguchi 2002). In life, and thus in death, the social position merited by those hunting dogs that proved to be skilled and valuable hunting tools was similar to that of skilled human hunters.

A comprehensive survey was undertaken of Jōmon dog burials in the archaeological literature (Japanese and Western language; details are available in the online supplementary material). Over 110 burials are identified from 39 archaeological sites (Figure 3). The dog burials discussed are all isolated burials: intentional, buried alone and with no obvious signs of butchery or human-induced death noted (cf. Perri in press). While 110 burials have been individually documented, some reports were ambiguous, noting only that dog burials were encountered. This implies the actual number of isolated burials is greater than 110. Importantly, isolated dog burials from Jōmon Japan are found almost exclusively in the eastern half of north-central Honshu, correlating with the deciduous forest-terrestrial ungulate economy of the Pacific Coast Jōmon. Burials begin in the Initial phase, with single burials at two sites, including the only example not located in north-central Honshu (Figure 4; Table 2). By the Early phase, burials occur farther north and in greater numbers. In the Middle phase, burials become more widespread across the Pacific coast of northcentral Honshu, with more sites and more burials. The Middle phase also has the only reported inland dog burial(s), although the number of animals and details are not given. Large numbers of sites and burials continue during the Late and Final phases, with burials widespread across the entire Pacific coast of north-central Honshu. After the Final phase the practice of dog burials seems to terminate, as dog burials are unknown in the ensuing (C) Antiquity Publications Ltd, 2016 


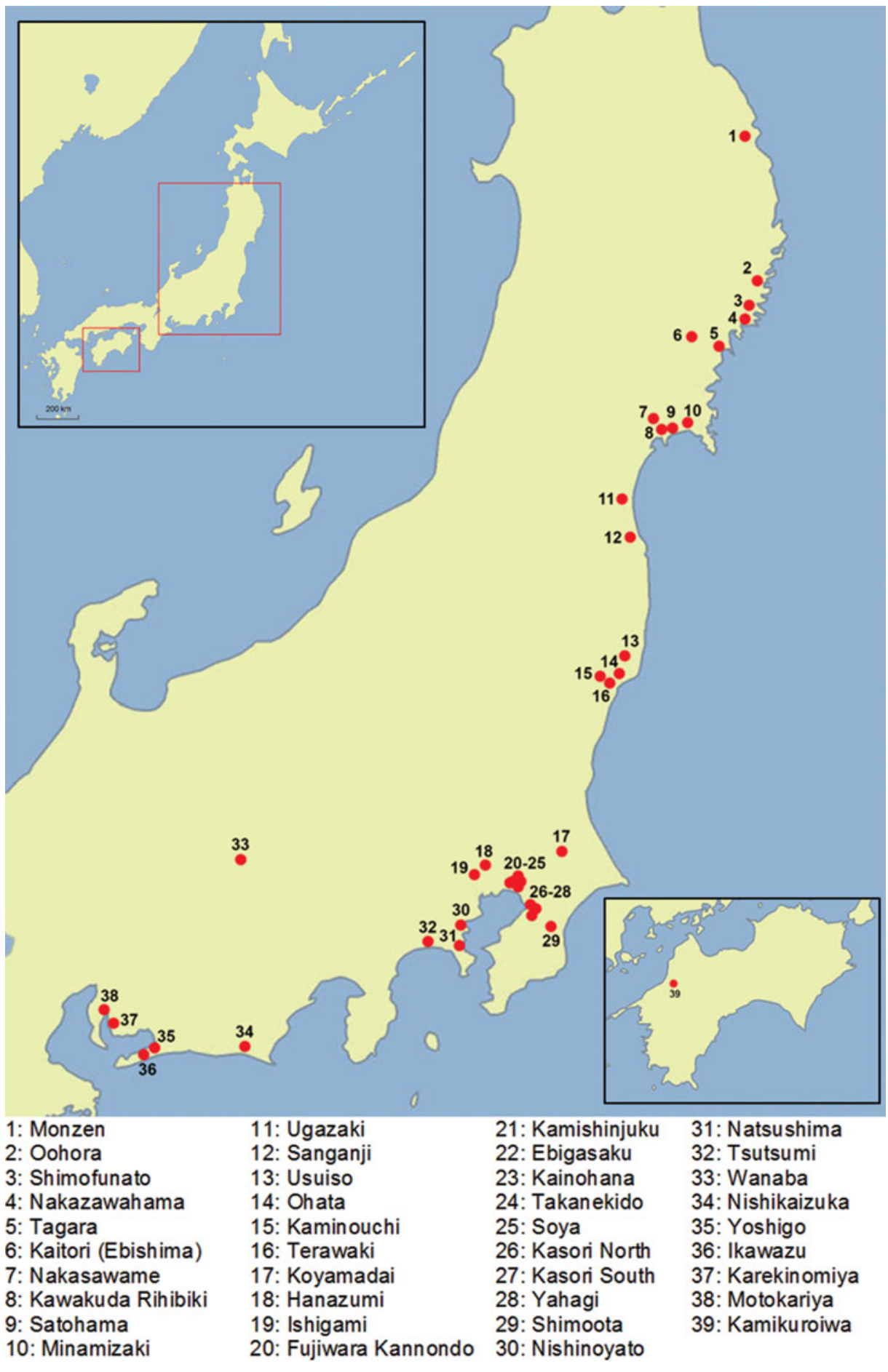

Figure 3. Locations of the isolated dog burials from Jömon Japan. 


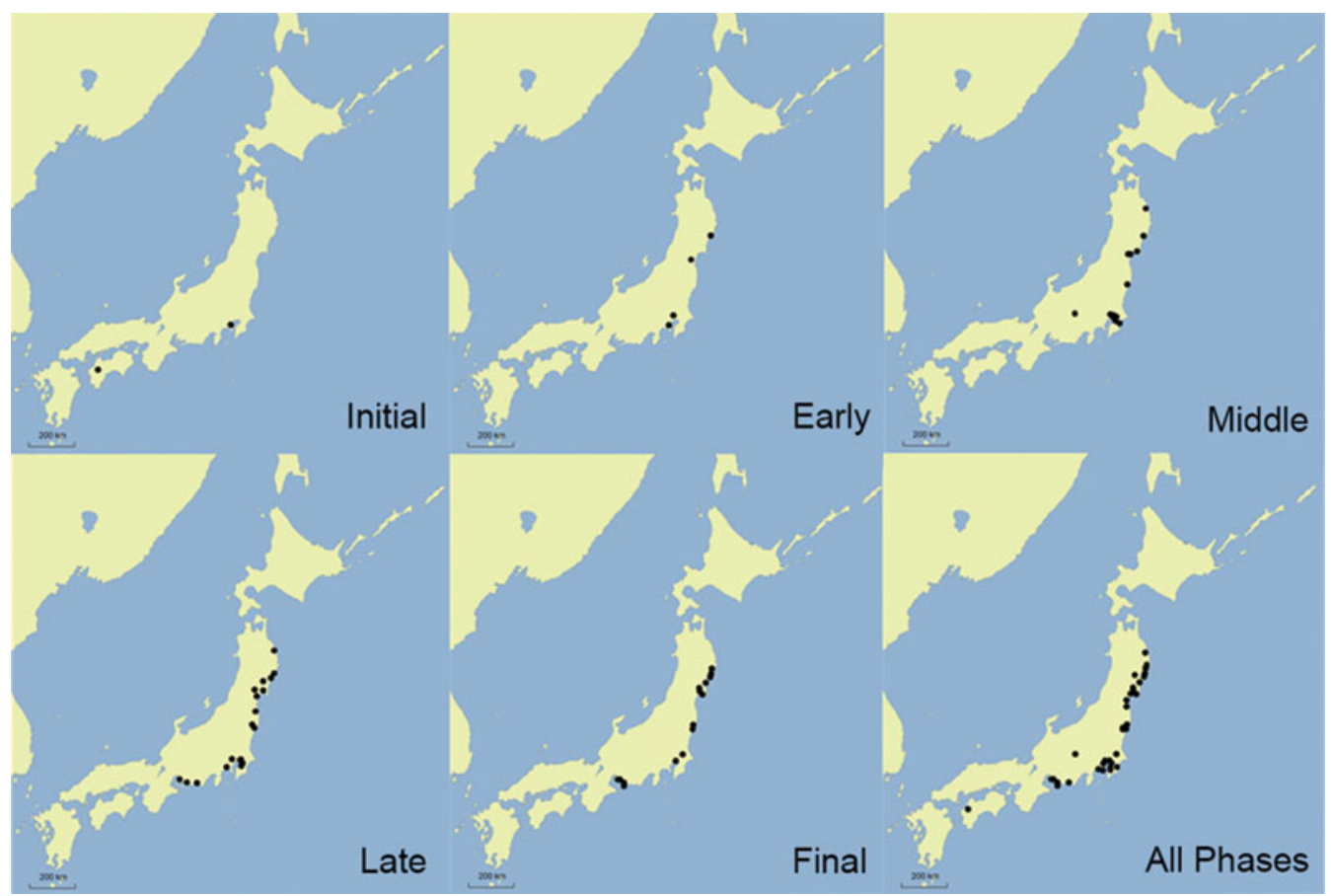

Figure 4. Sites with isolated dog burials from each Jömon chronological phase; multi-phase sites, in which burials are not attributed to one phase, are included across each phase of the site.

agricultural Yayoi period (beginning c. $2350 \mathrm{BP}$ ), further suggesting that dog burials are closely related to hunting activities during the Jōmon period.

The association between Jōmon dog burials and the deciduous forest-estuary ecotone is strongly supported by the fact that 37 of the 39 dog burial sites are shell middens. Injuries, mostly healed broken bones, were evident on dog remains from seven sites. It is possible these are related to the hunting of ungulates, as has been suggested for other prehistoric dogs (Warren 2004) and modern wolves (Mech \& Nelson 1990). The ages of the dogs range from newborn to over 12 years old. The burial of immature dogs may not normally be associated with those distinguished as capable hunters, yet the ethnographic record shows that puppies in hunter-gatherer groups are often valued for their potential as future hunting partners (e.g. Terashima 1983; Koster 2008), as Clutton-Brock (1995) has previously suggested for prehistoric puppies. Grave goods (an oyster shell bracelet; Horikoshi 1977) were noted from only one burial, although another dog burial was covered with stones (Otake 1983).

\section{Discussion}

The high proportion of dog remains at archaeological sites with evidence for intensive microlith use and ungulate subsistence has been one of the main arguments for the use of prehistoric hunting dogs (e.g. Aaris-Sørensen 1977; Clutton-Brock 1984). Although the burial of dogs has often been described as a Jōmon trait, their occurrence is not ubiquitous (C) Antiquity Publications Ltd, 2016 
across Jōmon Japan. Instead, they occur predominantly in a single region, where a significant focus on forest ungulate prey is documented. Even though the preservation of bone in shell middens is often better due to the calcium content (compared to the normally acidic, volcanic Japanese soil), the presence of dog burials in Pacific Honshu does not appear to be the result of differential preservation. Dog burials are not found in shell middens from other regions of Jōmon Japan, and scattered dog skeletal elements are found at most Jōmon sites without the presence of dog burials (see Kaneko 1978; Niwa 1987). The burials also do not appear to be a trait of one specific Jōmon population, but are present within several defined subgroups in the region (cf. Kobayashi et al. 1992), co-occurring with groups dependent on the deciduous forest-estuary ecotone. Dog burials from Pacific Coast Jōmon sites seem to reflect a specific subsistence lifeway, wherein sedentary populations, tied to static coastal resources (resulting in large shell middens), used hunting dogs to extract terrestrial game from nearby upland forests. While other site types (pit-dwellings and settlement sites) decreased after the Middle phase, the number of shell midden sites in Pacific Honshu stayed stable during the Middle and Late phases, with a slight increase in the Final phase (Habu et al. 2011), a pattern mirrored in the occurrence of dog burials (see Table 2).

It is also possible that hunting dogs played an important role in maximising hunting returns in an increasingly resource-strained seasonal environment. Rowley-Conwy (2001) and Torrence (2001) stress that when resources have to be procured in a short period, due to seasonality, hunting pressure or both, technology becomes more specialised. Davidson (1989) and Torrence (1989) also note the importance of reducing the risk of failure when dealing with a short seasonal hunting schedule, emphasising that every hunting episode needs to be successful. Horikoshi (1972) suggests that the territory of each Jōmon settlement in Tokyo Bay (Pacific Honshu) was only $2-3 \mathrm{~km}$ in radius, so that as populations increased and hunting territories decreased towards the end of the Jomon period, resources became strained. The hunting of younger deer, the collection of younger shellfish and an increased use of plant foods seen over time in Pacific Honshu further denotes subsistence pressure (Koike \& Ohtaishi 1985; Koike 1992). Given this demand on resources, the increasing number of dog burials during the later Jōmon phases may signify an increasing use of, and dependence on, hunting dogs as specialised technology to extract ungulate prey from nearby forests.

The importance of hunting dogs in this region is also demonstrated by the numerous dog-shaped clay figures $(\operatorname{dog} \bar{u})$, including a set that features a dog barking at three wild boar (Fujinuma 1997: 45). Dogs are minimally represented in the art of the subsequent agricultural Yayoi period (Hudson 1992). One Yayoi representation of dogs is found on a ceremonial bronze bell (dotaku) depicting a number of scenes, one of which is a boar surrounded by a hunter and a pack of dogs (Figure 5). Sahara (1982) argues that the scenes represent a temporal narrative, suggesting the boar-hunting human and dogs represent a way of life in the ancestral past (during the Jōmon period), prior to agricultural subsistence. This hypothesis is further supported by the abrupt termination of dog burials with the advent of agriculture around $2350 \mathrm{BP}$, which has previously been attributed to their loss of importance as hunting companions (Funk 2008). In contrast to the careful burial of the Jōmon dogs discussed here, the butchering and eating of dogs becomes a regular practice in later agricultural groups in Japan (Tanabe 2006). 


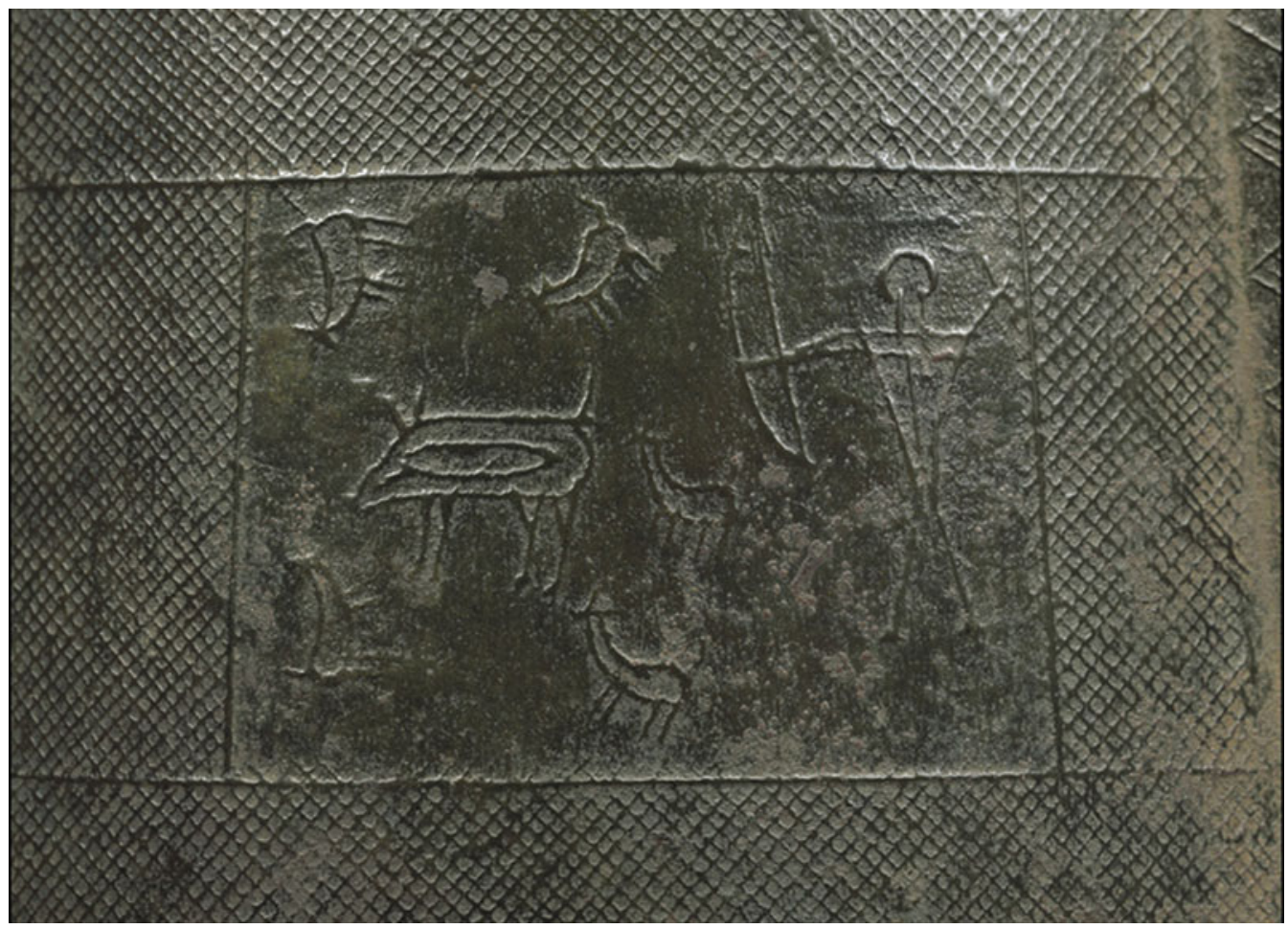

Figure 5. Ceremonial bronze bell (dotaku) from the Pacific Honshu region depicting a hunter with a bow and arrow hunting a wild boar, surrounded by a pack of dogs (image courtesy of the Tokyo National Museum).

The ethnographic record illustrates the importance of dogs in some deer- and boarhunting groups, as well as the revered treatment of these animals upon their death. The frequent burial of Jōmon dogs in such an intentional manner, sometimes with grave goods, may indicate that they held a similar position as valued hunting partners. These burials emulate the burials of humans from the same sites, individuals who are generally considered to be egalitarian, but who earned distinguished social positions through roles such as skilled hunters (Mizoguchi 2002; but see Watanabe 1990; Nakamura 2000). In Jōmon Japan, intentional dog burials are closely associated with a specific environment and subsistence economy, suggesting that dogs were valued as important forest hunting technology. An association between forest ungulate subsistence and intentional dog burials is seen not only in Jōmon Japan, but also in several other post-glacial deciduous forest forager groups (e.g. Bourque 1975; Larsson 1990; Morey \& Wiant 1992), suggesting that hunting dogs were a widespread adaptation to forest ungulate hunting in the northern temperate zone.

\section{Acknowledgements}

I would like to thank Akira Matsui, Masashi Maruyama, Hiroki Kikuchi and the researchers at the Nara National Research Institute for Cultural Properties for their assistance during my time in Japan. I would also like to thank Peter Bleed and Simon Kaner for their helpful comments on this manuscript. This research was partially funded by the British Association for Japanese Studies, the Great Britain Sasakawa Foundation, the Japan Foundation, the Tweedie Exploration Fellowship and the Rosemary Cramp Fund.

C Antiquity Publications Ltd, 2016 


\section{Supplementary material}

To view supplementary material for this article, please visit http://dx.doi.org/ 10.15184/aqy.2016.115.

\section{References}

AARIS-SøRENSEN, K. 1977. Vedbæk-jægeren og hans hunde, Vedbækprojektet. I marken og in museerne. Søllerødbogen 1977: 170-76.

Aikens, C.M. \& T. AKazaWA. 1996. The Pleistocene-Holocene transition in Japan and adjacent Northeast Asia, in L.G. Straus, B.V. Eriksen, J. Erlandson \& D.R. Yesner (ed.) Humans at the end of the Ice Age: 215-27. New York: Springer.

Aikens, C.M. \& T. Higuchi. 1982. Prehistory of Japan. New York: Academic.

Aikens, C.M., K.M. Ames \& D. SAnger. 1986. Affluent collectors at the edges of Eurasia and North America: some comparisons and observations on the evolution of society among north-temperate coastal hunter-gatherers, in T. Akazawa \& C.M. Aikens (ed.) Prehistoric hunter-gatherers in Japan: new research methods: 3-26. Tokyo: University Museum, University of Tokyo.

AKAZAWA, T. 1986. Regional variation in procurement systems of Jōmon hunter-gatherers, in T. Akazawa \& C.M. Aikens (ed.) Prehistoric hunter-gatherers in Japan: new research methods: 73-89. Tokyo: University Museum, University of Tokyo.

BINFORD, L.R. 1980. Willow smoke and dogs' tails: hunter-gatherer settlement systems and archaeological site formation. American Antiquity 45: 4-20. http://dx.doi.org/10.2307/279653

Bleed, P. \& A. Matsui. 2010. Why didn't agriculture develop in Japan? A consideration of Jōmon ecological style, niche construction, and the origins of domestication. Journal of Archaeological Method and Theory 17: 356-70. http://dx.doi.org/10.1007/s10816-010-9094-8

Bourque, B.J. 1975. Comments on the late Archaic populations of central Maine: the view from the Turner Farm. Arctic Anthropology 12: 35-45.

Bulmer, R. 1968. The strategies of hunting in New Guinea. Oceania 38: 302-18. http://dx.doi.org/ 10.1002/j.1834-4461.1968.tb00975.x

Chitwood, M.C., M.N. Peterson \& C.S. Deperno. 2011. Assessing dog hunter identity in coastal North Carolina. Human Dimensions of Wildlife 16: 128-41. http://dx.doi.org/10.1080/10871209.2011.551448

Churchill, S.E. 1993. Weapon technology, prey-size selection, and hunting methods in modern hunter-gatherers: implications for hunting in the Palaeolithic and Mesolithic. Archeological Papers of the American Anthropological Association 4: 11-24. http://dx.doi.org/10.1525/ap3a.1993.4.1.11

Clutton-Brock, J. 1984. Dog, in I.L. Mason (ed.) Evolution of domesticated animals. London: Longman.

- 1995. Origins of the dog: domestication and early history, in J. Serpell (ed.) The domestic dog: its evolution, behaviour, and interactions with people: 7-20. Cambridge: Cambridge University Press.

DAVIDSON, I. 1989. Is intensification a condition of the fisher-hunter-gatherer way of life? Archaeology in Oceania 24: 75-78. http://dx.doi.org/10.1002/j. 1834-4453.1989.tb00215.x

Davis, S. 1982. The taming of the few. New Scientist 95: 697-700.

DWYER, P.D. 1983. Etolo hunting performance and energetics. Human Ecology 11: 145-74. http://dx.doi.org/10.1007/BF00891741

ELLEN, R. 1999. Categories of animality and canine abuse. Exploring contradictions in Nuaulu social relationships with dogs. Anthropos 94: 57-68.

Friss-HANSEN, J. 1990. Mesolithic cutting arrows: functional analysis of arrows used in the hunting of large game. Antiquity 64: 494-504. http://dx.doi.org/10.1017/S0003598X0007839X

FujINUMA, K. 1997. Jōmon no dogu (Rekishi hakkutsu). Tokyo: Kodansha (in Japanese).

FUNK, H. 2008. Introduction, in K. Hasebe (ed.) On the skulls and lower jaws of the Japanese Stone Age dog races: 5-99. Paderborn: Lykos.

Grøn, O. \& M.G. Turov. 2007. Resource 'pooling' and resource management. An ethno-archaeological study of the Evenk hunter-gatherers, Katanga County, Siberia, in B. Hårdh, K. Jennbert \& D. Olausson (ed.) On the road: studies in honour of Lars Larsson (Acta Archaeologica Lundensia 26): 67-72. Stockholm: Almqvist \& Wiksell.

HabU, J. 2004. Ancient Jomon of Japan. Cambridge: Cambridge University Press. 
Habu, J., A. Matsui, N. Yamamoto \& T. Kanno. 2011. Shell midden archaeology in Japan: aquatic food acquisition and long-term change in the Jōmon culture. Quaternary International 239: 19-27. http://dx.doi.org/10.1016/j.quaint.2011.03.014

Hongo, H., T. AnezaKi, K. YamaZAKI, O. TAKaHASHI \& H. SugaWAra. 2007. Hunting or management? The status of Sus in the Jomon period in Japan, in U. Albarella, K. Dobney, A. Ervynck \& P. Rowley-Conwy (ed.) Pigs and humans: 10,000 years of interaction: 109-30. Oxford: Oxford University Press.

HoriKOSHI, M. 1972. Settlements and community system of the Jōmon period. Sundai Shigaku 31: $1-29$

- 1977. Briefing of excavation at Soya Shell Midden, D Area. Ichikawa: Education Board of Ichikawa City.

HOOVER, K.C. \& F. Williams. In press. Variation in regional diet and mandibular morphology in prehistoric Japanese hunter-gatherer-fishers. Quaternary International.

Hudson, M.J. 1992. Rice, bronze, and chieftains: an archaeology of Yayoi ritual. Japanese Journal of Religious Studies 19: 139-89.

IKEYA, K. 1994. Hunting with dogs among the San in the Central Kalahari. African Study Monographs 15: 119-34.

INADA, T. 1986. Jōmon bunka no keisei. Nihon Koukogaku 6: 65-117 (in Japanese).

KaneKo, H. 1978. Dōbutsu wa, jōmon jidai no iseki kara no mama (2). Koukogaku Note 7: 1-18 (in Japanese).

Kitagawa, J. \& Y. Yasuda. 2008. Development and distribution of Castanea and Aesculus culture during the Jōmon period in Japan. Quaternary International 184: 41-55. http://dx.doi.org/10.1016/j.quaint.2007.09.014

KNIGHT, J. 2003. 'Indigenous' regionalism in Japan, in R. Ellen, P. Parkes \& A. Bicker (ed.) Indigenous environmental knowledge and its transformations: critical anthropological perspectives: 151-76. New York: Harwood Academic.

KOBAYASHI, T. 2004. Jōmon reflections: forager life and culture in the prehistoric Japanese archipelago. Oxford: Oxbow.

Kobayashi, T., M. Hudson \& M. Yamagata. 1992. Regional organization in the Jōmon period. Arctic Anthropology 29: 82-95.

KOIKE, H. 1986. Prehistoric hunting pressure and paleobiomass: an environmental reconstruction and archaeozoological analysis of a Jōmon shellmound area, in T. Akazawa \& C.M. Aikens (ed.) Prehistoric hunter-gatherers in Japan: new research methods: 27-53. Tokyo: University Museum, University of Tokyo.

(C) Antiquity Publications Ltd, 2016
- 1992. Exploitation dynamics during the Jōmon period, in C.M. Aikens \& S.N. Rhee (ed.) Pacific Northeast Asia in prehistory: 53-58. Pullman: Washington State University Press.

Koike, H. \& N. OHTAishi. 1985. Prehistoric hunting pressure estimated by the age composition of excavated sika deer (Cervus nippon) using the annual layer of tooth cement. Journal of Archaeological Science 12: 443-56. http://dx.doi.org/10.1016/0305-4403(85)90004-4

KOJIMA, H. \& M. KIKUCHI. 1999. Jōmon jidai ni okeru inu no shiyō no mondai ni tsuite,-to Shibuya-ku Toyozawa kaidzuka no kēsu o hakkutsu. Kaidzuka boryūmu 54: 1-18 (in Japanese).

Koler-Matznick, J., B. Yates, S. Bulmer \& I.L. BrisBin JR. 2007. The New Guinea singing dog: its status and scientific importance. Australian Mammology 29: 47-56. http://dx.doi.org/10.1071/AM07005

Koster, J.M. 2008. Hunting with dogs in Nicaragua: an optimal foraging approach. Current Anthropology 49: 935-44. http://dx.doi.org/10.1086/592021

KraUs, B. 1953. An outline of Japan's prehistoric cultures. Memoirs of the Society for American Archaeology 9: 12-16.

LARSSON, L. 1990. Dogs in fraction-symbols in action, in P.M. Vermeersch \& P. Van Peer (ed.) Contributions to the Mesolithic in Europe: 153-60. Leuven: Leuven University Press.

MECH, L.D. \& M.E. NeLSON. 1990. Evidence of prey-caused mortality in three wolves. American Midland Naturalist 123: 207-208. http://dx.doi.org/10.2307/2425775

Melis, C., B. JęDrZejewsKa, M. ApOllonio, K.A. BARTOŃ, W. JęDRZEJEWSKI, J.D.C. LinNELL, I. Kojola, J. KusaK, M. Adamic \& S. Ciuti. 2009. Predation has a greater impact in less productive environments: variation in roe deer (Capreolus capreolus) population density across Europe. Global Ecology and Biogeography 18: 724-34. http: //dx.doi.org/10.1111/j.1466-8238.2009.00480.x

Mellars, P. 1975. Ungulate populations, economic patterns and the Mesolithic landscape, in J.G. Evans, S. Limbrey \& H. Cleere (ed.) The effect of man on the landscape: the Highland Zone (Council for British Archaeology 11): 49-56. Nottingham: Derry \& Sons.

MinagaWA, M. 2001. Hone tanpakushitsu de antei tanso chisso dōi-tai kara suisoku senshijidaino nihonjin no shokuji patān. Bulletin of the National Museum of Japanese History 86: 333-57 (in Japanese with English summary).

MinaKI, M. 1988. Yoneizumi iseki no ogata shokubutsu kaseki, in Kanazawa shi, Yoneizumi site, Ishikawa Kenritsu Maizoubunkazai Sennta (Yoneizumi site report): 279-96. Kanazawa: Ishikawa Prefectural Archaeological Centre (in Japanese). 


\section{Hunting dogs as environmental adaptations in Jömon Japan}

Mitchell, P. 2008. The canine connection: dogs and southern African hunter-gatherers, in S. Badenhorst, J.C. Driver \& P. Mitchell (ed.) Animals and people: archaeozoological papers in honour of Ina Plug (British Archaeological Reports international series 26): 104-16. Oxford: Archaeopress.

MizoguCHI, K. 2002. An archaeological history of Japan: 10,000 B.C. to A.D. 700. Philadelphia: University of Pennsylvania Press.

Morey, D.F. \& M.D. Wiant. 1992. Early Holocene domestic dog burials from the North American Midwest. Current Anthropology 33: 224-29. http://dx.doi.org/10.1086/204059

NaKamura, O. 2000. Saishu Shuryo-min no Fukuso Koi. Kikan Kokogaku 70: 19-23 (in Japanese).

Ngima Mawoung, G. 2006. Perception of hunting, gathering and fishing techniques of the Bakola of the coastal region, southern Cameroon. African Study Monographs 33: 49-70.

NishinaKagaWa, H., M. Matsumoto, J. OtsuKa \& S. KaWAGUCHI. 1994. Mammals from archaeological sites of the Jōmon period in Kagoshima Prefecture. Journal of the Mammalogical Society of Japan 19: 57-66.

NiwA, Y. 1987. To understand the real image of the ancient Japanese dogs. Kiba 2: 5-29.

OlOwO OJOADE, J. 1990. Nigerian cultural attitudes to the dog, in R. Willis (ed.) Signifying animals: human meaning in the natural world: 215-21. London: Routledge.

OTAKE, K. 1983. Jōmonjin wa kossetsu shita ashi de inu o atsukaimasu. Anima 121: 11 (in Japanese).

PANnell, S. \& S. O’ConNOR. 2010. Strategy blurring: flexible approaches to subsistence in East Timor, in K. Hardy (ed.) Archaeological invisibility and forgotten knowledge: 115-30. Oxford: Archaeopress.

PERri, A. In press. A typology of dog deposition in archaeological contexts, in P. Rowley-Conwy, P. Halstead \& D. Serjeanstson (ed.) Bone Man: essays in memory of Tony Legge-hunter, fisherman, fowler and zooarchaeologist. Oxford: Oxbow.

ROWLEY-CONWY, P.A. 1986. Between cave painters and crop planters: aspects of the temperate European Mesolithic, in M. Zvelebil (ed.) Hunters in transition: Mesolithic societies of temperate Eurasia and their transition to farming: 17-32. Cambridge: Cambridge University Press.

- 2001. Time, change and the archaeology of hunter-gatherers: how original is the 'original affluent society', in C. Panter-Brick, R. Layton \& P. Rowley-Conwy (ed.) Hunter-gatherers: an interdisciplinary perspective: 39-72. Cambridge: Cambridge University Press.
RÜHe, F., A. Baumgart \& T. Riemer. 2006. Tracking down wounded game with the aid of Hannoverian bloodhounds: the effect of the acoustic tie of the dog handler to his chasing hound on the lengths of the chases and on the tracking success. Allgemeine Forst-und Jagdzeitung 177: 91-96.

Saİd, S., V. Tolon, S. Brandt \& E. Baubet. 2012. Sex effect on habitat selection in response to hunting disturbance: the study of wild boar. European Journal of Wildlife Research 58: 107-15. http://dx.doi.org/10.1007/s10344-011-0548-4

SAHARA, M. 1982. 34 no Canpus: Rensaku 4 Dotaku no kaiga no 'bunpo', in K. Tsuboi (ed.) Kokogaku Ronko: 245-80. Tokyo: Heibon Sha (in Japanese).

ShigeHARA, N. 1985. Kodai no ie no inu no shisutemu to idō ni kansuru kenkyū [Studies on the genealogy and migration of the ancient domesticated dogs]. Kagaku kenkyū no tame no kyōiku-hi hojokin (kenkyū A) kenkyū hōkoku-sho-shō. Research report for the 1984 Ministry of Education, Science and Culture Research Grant (Research A). Research no. 58340056 (in Japanese).

TANABE, Y. 2006. Phylogenetic studies of dogs with emphasis on Japanese and Asian breeds. Proceedings of the Japan Academy 82: 375-87. http://dx.doi.org/10.2183/pjab.82.375

Terashima, H. 1983. Mota and other hunting activities of the Mbuti archers: a socio-ecological study of subsistence technology. African Study Monographs 3: 71-85.

TORRENCE, R. 1989. Tools as optimal solutions, in $\mathrm{R}$. Torrence (ed.) Time, energy and stone tools: 1-6. Cambridge: Cambridge University Press.

- 2001. Hunter-gatherer technology: macro-and microscale approaches, in C. Panter-Brick, R. Layton \& P. Rowley-Conwy (ed.) Hunter-gatherers: an interdisciplinary perspective: 73-98. Cambridge: Cambridge University Press.

TsujI, S. 1997. A land ecosystem in the transition to the Jōmon Age. The Quaternary Research 36: 309-18 (in Japanese with English summary).

- 2001. Jōmon teki seitaikei to hito [Jomon ecosystems and humans]. Nihon-jin Harukana Tabi. Tokyo: NHK.

Tsujino, R., E. IsHimaru \& T. Yumoto. 2010. Distribution patterns of five mammals in the Jōmon period, middle Edo period, and the present, in the Japanese Archipelago. Mammal Study 35: 179-89. http://dx.doi.org/10.3106/041.035.0304

TsuKaDA, M. 1986. Vegetation in prehistoric Japan: the last 20,000 years, in R. Pearson, G. Barnes \& K.L. Hutterer (ed.) Windows on the Japanese past: studies in archeology and prehistory: 11-56. Ann Arbor: University of Michigan Press. 


\section{Angela R. Perri}

UCHIYAMA, J. 2006. The environmental troublemaker's burden? Jōmon perspectives on foraging land-use change, in C. Grier, J. Kim \& J. Uchiyama (ed.) Beyond affluent foragers: rethinking hunter-gatherer complexity: 136-67. Oxford: Oxbow.

UNDERHILl, A.P. \& J. HABU. 2006. Early communities in East Asia: economic and sociopolitical organization at the local and regional levels, in M. Stark (ed.) Archaeology of Asia: 121-48. Oxford: Blackwell.

http://dx.doi.org/10.1002/9780470774670.ch7
WARREN, D. 2004. Skeletal biology and paleopathology of domestic dogs from prehistoric Alabama, Illinois, Kentucky and Tennessee. Unpublished PhD dissertation, Indiana University.

WATANABE, H. 1990. Jōmon seisō gakkai [Jōmon stratified society]. Tokyo: Rokko Shuppan (in Japanese).

YASUDA, Y. 1978. Prehistoric environment in Japan: palynological approach. Sendai: Tohoku University.

Received: 29 January 2015; Accepted: 20 May 2015; Revised: 17 July 2015

(C) Antiquity Publications Ltd, 2016 